\title{
Regional differences in outcomes of nonvariceal upper gastrointestinal bleeding in Saskatchewan
}

\author{
Michael O'Byrne MD¹, Erin L Smith-Windsor PhD ${ }^{1}$, Chris R Kenyon MD², \\ Sanchit Bhasin $\mathrm{MD}^{3}$, Jennifer L Jones MD MSC FRCPC ${ }^{1,4}$
}

M O'Byrne, EL Smith-Windsor, CR Kenyon, S Bhasin, JL Jones. Regional differences in outcomes of nonvariceal upper gastrointestinal bleeding in Saskatchewan. Can J Gastroenterol Hepatol 2014;28(3):135-139.

BACKGROUND: Nonvariceal upper gastrointestinal bleeding (NVUGIB) is associated with significant mortality.

OBJECTIVE: To examine several factors that may impact the mortality and 30-day rebleed rates of patients presenting with NVUGIB.

METHODS: A retrospective study of the charts of patients admitted to hospital in either the Saskatoon Health Region (SHR) or Regina Qu'Appelle Health Region (RQHR) (Saskatchewan) in 2008 and 2009 was performed. Mortality and 30-day rebleed end points were stratified according to age, sex, day of admission, patient status, health region, specialty of the endoscopist and time to endoscopy. Logistic regression modelling was performed, controlling for the Charlson comorbidity index, age and sex as covariates.

RESULTS: The overall mortality rate observed was $12.2 \%(n=44)$, while the overall 30 -day rebleed rate was $20.3 \%(n=80)$. Inpatient status at the time of the rebleeding event was associated with a significantly increased risk of both mortality and rebleed, while having endoscopy performed in the RQHR versus SHR was associated with a significantly decreased risk of rebleed. A larger proportion of endoscopies were performed both within $24 \mathrm{~h}$ and by a gastroenterologist in the RQHR.

CONCLUSION: Saskatchewan has relatively high rates of mortality and 30-day rebleeding among patients with NVUGIB compared with published rates. The improved outcomes observed in the RQHR, when compared with the SHR, may be related to the employ of a formal call-back endoscopy team for the treatment of NVUGIB.

Key Words: 30-day rebleeding; Endoscopy; Mortality; Nonvariceal upper gastrointestinal bleeding

$\mathrm{N}^{2}$ onvariceal upper gastrointestinal bleeding (NVUGIB) is a significant cause of hospitalization, with an incidence of 50 to 150 hospitalizations per 100,000 population $(1,2)$. Unfortunately, there remains significant mortality associated with this condition, with recently reported rates ranging from $3.5 \%$ to $5.4 \%$ in Canada (3-5). Given this high mortality, risk stratification on presentation with NVUGIB is of great importance to correctly triage patients so that appropriate medical and therapeutic management may be implemented in a timely fashion. Patients at higher risk for rebleeding or mortality can be identified by risk factors such as increased age, hypotension, major stigmata of recent hemorrhage or comorbidities such as malignancy, or cardiac, renal or liver failure (6). In contrast, hemoglobin levels $\geq 130 \mathrm{~g} / \mathrm{L}$ for men or $\geq 120 \mathrm{~g} / \mathrm{L}$ for women, blood urea level $<6.5 \mathrm{mmol} / \mathrm{L}$, systolic blood pressure $\geq 110 \mathrm{mmHg}$, heart rate $<100$ beats/min, and the absence of syncope, melena and comorbidities are indicative of patients who are at low risk for rebleeding

\author{
Les différences régionales de résultats des \\ saignements œesogastroduodénaux non variqueux en \\ Saskatchewan
}

HISTORIQUE : Les saignements œesogastroduodénaux non variqueux (SOGDNV) s'associent à une mortalité importante.

OBJECTIF : Examiner plusieurs facteurs susceptibles d'influer sur le taux de mortalité et de reprise des saignements au bout de 30 jours chez des patients ayant des SOGDNV.

MÉTHODOLOGIE : Les chercheurs ont procédé à l'étude rétrospective des dossiers des patients hospitalisés dans la région sanitaire de Saskatoon (RSS) ou la région sanitaire Regina Qu'Appelle (RSRQ) (Saskatchewan) en 2008 et 2009. Ils ont stratifié les paramètres ultimes de mortalité et de reprise des saignements au bout de 30 jours selon l'âge, le sexe, le jour d'hospitalisation, la situation du patient, la région sanitaire, la spécialité de l'endoscopiste et le moment de l'endoscopie. Ils ont utilisé un modèle de régression logistique pour contrôler les covariables suivantes : indice de comorbidité de Charlson, âge et sexe.

RÉSULTATS : Le taux global de mortalité observé s'élevait à 12,2\% $(\mathrm{n}=44)$, et le taux de reprise des saignements au bout de 30 jours, à $20,3 \%(n=80)$. L'hospitalisation au moment de la reprise des saignements s'associait à un risque considérablement plus élevé de mortalité et de reprise des saignements, tandis que l'exécution de l'endoscopie dans la RSRQ plutôt que la RSS s'associait à un risque considérablement réduit de reprise des saignements. Une plus forte proportion d'endoscopies était effectuée à la fois dans les 24 heures et par une gastroentérologue de la RSRQ.

CONCLUSION : La Saskatchewan présente un taux relativement élevé de mortalité et de reprise des saignements au bout de 30 jours chez les patients ayant des SOGDNV par rapport aux taux publiés. Les meilleurs résultats obtenus dans la RSRQ par rapport à la RSS peuvent être liés à l'utilisation d'une équipe d'endoscopie de rappel officielle pour le traitement des SOGDNV.

and mortality $(7,8)$. Risk stratification has been found to be useful for identifying patients who require therapeutic intervention, and not only minimizes unnecessary hospitalizations (8) but also decreases the lengths of stay for patients who are hospitalized $(9,10)$.

It is currently recommended that patients who require endoscopy undergo this procedure within $24 \mathrm{~h}$ of presenting to hospital with NVUGIB $(11,12)$ because endoscopic findings can be useful in determining which patients are at low risk for rebleeding and who can, therefore, be safely managed as outpatients (10). Early endoscopy has also been found to decrease the risk of rebleeding and surgery (13), as well as the length of hospital stay required by a patient $(10,11,14)$. Treating patients with proton pump inhibitors (PPIs) following endoscopy is also recommended $(12,15)$ because the use of these drugs in combination with endoscopy has been associated with decreased rebleeding and mortality in patients with high-risk stigmata (3).

\footnotetext{
${ }^{1}$ Division of Gastroenterology, Department of Medicine; ${ }^{2}$ Department of Surgery; ${ }^{3}$ Division of General Internal Medicine, Department of Medicine;

${ }^{4}$ Department of Community Health and Epidemiology, University of Saskatchewan, Saskatoon, Saskatchewan

Correspondence and reprints: Dr Jennifer L Jones, Departments of Medicine and Community Health and Epidemiology, Division of Gastroenterology,

Department of Medicine, Royal University Hospital, 103 Hospital Drive, Saskatoon, Saskatchewan S7N OW8. Telephone 306-966-7985,

fax306-966-7996,e-mail j.jones@usask.ca
} 
TABLE 1

Patient characteristics

\begin{tabular}{lccc}
\hline Characteristic & $\%(\mathbf{n} /$ total) & Mean (95\% Cl) & Min/Max \\
\hline Demographics & & $66.5(64.8-68.2)$ & $17 / 100$ \\
Age, years & & \\
Male sex, \% & $61.7(222 / 360)$ & & \\
Inpatients, \% & $79.1(285 / 360)$ & & \\
Endoscopist & & & \\
Gastroenterologist & $64.1(231 / 360)$ & & \\
General surgeon & $33.9(122 / 360)$ & & \\
Other & $1.9(7 / 360)$ & & \\
Location, SHR & $50.2(181 / 360)$ & & \\
Protion pump inhibitor administration & & \\
Overall & $94.4(340 / 360)$ & & \\
By infusion & $91.5(311 / 340)$ & & \\
Medication at presentation & & & \\
Acetylsalicyclic acid & $23.6(85 / 360)$ & & \\
NSAIDs & $14.7(53 / 360)$ & & \\
Clopidogrel (Plavix*) & $6.9(25 / 360)$ & & \\
Warfarin & $13.9(50 / 360)$ & & \\
Charlson comorbidity index & & $2.7(2.4-3.0)$ & \\
\hline
\end{tabular}

*Bristol-Myers Squibb, USA. Max Maximum; Min Minimum; NSAIDs Nonsteroidal anti-inflammatory drugs; SHR Saskatoon Health Region

Several factors have been found to influence NVUGIB outcomes including the experience of the endoscopist, weekend versus weekday admission, hospital volume, length of time to endoscopy and admission to specialized units. For example, there is a significantly greater chance of rebleeding and an increased need for blood transfusion following endoscopies performed by operators with less experience (16). Patients who are admitted on a weekend are also less likely to undergo early endoscopy and have higher mortality rates than those admitted during the work week $(14,17)$. In addition, patients treated at hospitals that encounter a high volume of patients have significantly reduced mortality rates compared with those treated in low-volume centres, potentially due to procedures being performed by more experienced endoscopists, as well as to better access to endoscopy and support care (18). Significantly, admittance to specialized gastroenterology units has also been found to result in lower mortality (19-23), and having processes such as admission to a specialized hospital unit and the availability of an endoscopy on-call nurse in place may also lead to more favourable NVUGIB outcomes (24).

Within Saskatchewan, which has one of the lowest number of gastroenterologists per capita in Canada (25), significant differences exist between the Saskatoon Health Region (SHR) and the Regina Qu'Appelle Health Region (RQHR) with respect to their approaches to NVUGIB treatment. The current study examined NVUGIB mortality and 30-day rebleed rates in both health regions to determine the influence of selected system-, operator- and patient-related variables on these outcomes.

\section{METHODS}

\section{Patient identification}

A retrospective study of the charts of patients admitted to hospital in either the SHR or the RQHR between January 1, 2008 and December 31, 2009 was performed to identify patients with either a primary or secondary diagnosis of NVUGIB, as indicated by K92.x International Classification of Diseases, 10th Revision codes. The SHR and RQHR are the two tertiary care centres in Saskatchewan, with a catchment population of approximately 1.2 million. Inclusion criteria included the presence of hematemesis, melena and syncope, while patients with evidence of a lower gastrointestinal source of bleeding or esophageal varices were excluded. In total, 412 charts were reviewed, with 360 meeting the
TABLE 2

Endoscopic information

\begin{tabular}{lccc}
\hline $\begin{array}{l}\text { Forrest } \\
\text { classification* }\end{array}$ & $\begin{array}{c}\text { Proportion, } \\
\% \pm \text { SE }\end{array}$ & Mortality rate, \% & $\begin{array}{c}\text { Rebleed rate, } \\
\% \pm \text { SE }\end{array}$ \\
\hline IA & $7.41 \pm 1.79$ & 25.0 & $37.5 \pm 12.5$ \\
IB & $25.0 \pm 2.95$ & 5.6 & $25.9 \pm 6.0$ \\
IIA & $15.3 \pm 2.45$ & 9.1 & $18.2 \pm 6.8$ \\
IIB & $12.5 \pm 2.26$ & 14.8 & $51.9 \pm 9.8$ \\
IIC & $7.87 \pm 1.84$ & 5.9 & $11.8 \pm 8.1$ \\
III & $31.5 \pm 3.17$ & 10.1 & $10.3 \pm 3.7$ \\
\hline
\end{tabular}

*IA Spurting hemorrhage; IB Oozing hemorrhage; IIA Visible vessel; IIB Adherent clot; IIC Pigmented lesion; III No signs of recent hemorrhage

inclusion criteria. The present study was approved by the University of Saskatchewan (Saskatoon, Saskatchewan) and the RQHR Biomedical Ethics Review Boards.

\section{Data abstraction}

Data abstracted from chart review included baseline demographic variables (age and sex), medication-related variables (use of acetylsalicylic acid, clopidogrel [Plavix, Bristol-Myers Squibb, USA], nonsteroidal anti-inflammatory drugs or warfarin), and illness burden as measured by the Charlson comorbidity index (CCI). The CCI was used to adjust for comorbid illness as a potential confounder in risk estimate assessment (26). The severity of NVUGIB at presentation was determined using clinical and endoscopic risk stratification tools including Glasgow-Blatchford and Rockall scores, and endoscopic lesions were categorized according to Forrest classification. The administration of PPIs postendoscopy and the specialty of the endoscopic operator were recorded, as were mortality and rebleed events that occurred during the 30 days following initial presentation.

\section{Assessment of outcomes}

The primary outcomes investigated in the present study were mortality and rebleeding within 30 days of initial presentation. A rebleed was defined by signs of NVUGIB accompanied by either a 15-point reduction in hemoglobin level within $24 \mathrm{~h}$ to $48 \mathrm{~h}$, or endoscopic evidence of recent gastrointestinal hemorrhage. These outcomes were categorized for logistic regression modelling using the following categories: age, sex, health region (SHR or RQHR), specialty of the endoscopist (gastroenterologist or general surgeon), time to endoscopy (within or later than $24 \mathrm{~h}$ following presentation), patient status (inpatient or outpatient) and day of admission (weekend or weekday).

\section{Statistical methods}

Baseline demographic and patient characteristics were analyzed using descriptive statistics such as mean, range and proportion. A sample size of $142(n=71)$ was calculated to detect a $7 \%$ difference in mortality and rebleed rate between health regions with $80 \%$ power (for basic group comparisons of proportions). Pearson $\chi^{2}$ analysis was used to perform group comparisons of proportions. Logistic regression modelling was performed to control for potentially confounding covariates including age, CCI, health region (SHR versus RQHR), sex, specialty of the endoscopist (gastroenterologist or general surgeon), time to endoscopy (within or later than $24 \mathrm{~h}$ following presentation), patient status (inpatient or outpatient) and day of admission (weekend or weekday). STATA version 10.0 (StataCorp LP, USA) was used for all statistical analyses, with statistical significance set at 0.05 .

\section{RESULTS}

Between January 1, 2008 and December 31, 2009, 360 patients were treated for NVUGIB in the SHR $(n=181)$ and RQHR $(n=179)$. The baseline characteristics of the patients included in the study are summarized in Table 1. Endoscopic findings were used to risk stratify patients (Table 2). The etiology of UGIB was also documented (Table 3). Of the patients included in the present study, 35.3\% $(n=127)$ required 
TABLE 3

\section{Causes of gastrointestinal bleed $(n=417)$}

\begin{tabular}{lc}
\hline Cause & $\mathbf{n}(\%)$ \\
\hline Peptic ulcer disease & $217(52.04)$ \\
Variceal & $57(13.67)$ \\
Normal & $46(11.03)$ \\
Gastritis & $36(8.63)$ \\
Esophagitis & $33(7.91)$ \\
Angiodysplasia & $12(2.88)$ \\
Other & $10(2.40)$ \\
Malignancy & $5(1.20)$ \\
Missing & $1(0.24)$ \\
\hline
\end{tabular}

intervention at the time of their endoscopy. As expected, Forrest classification was significantly associated with rebleed rate and mortality $(\mathrm{P}<0.01)$.

The mortality rate for patients presenting with NVUGIB was $12.2 \%(n=44)$, while the 30 -day rebleed rate was $20.3 \%(n=73)$. The odds of mortality was significantly higher in inpatients versus outpatients. The odds of mortality was not influenced by health region, endoscopist specialty, time from admission to esophagogastroduodenoscopy (EGD), patient age, sex or CCI (Figure 1). On univariate analysis, the rebleed rate was found to be associated with inpatient status, health region in which the patient was treated and the specialty of the physician performing the endoscopy (Figure 2). Patients in the SHR were much less likely to undergo endoscopy within $24 \mathrm{~h}$ of presentation compared with patients in the RQHR (OR 0.33 [95\% CI 0.20 to 0.57]). Patients undergoing endoscopy by general surgeons were more likely to wait $>24 \mathrm{~h}$ for endoscopy (OR 2.16 [95\% CI 1.30 to 3.59]). A proportionately larger number of endoscopies in the RQHR were performed by gastroenterologists ( $79 \%$ versus $49.7 \%$ in the SHR).

Comorbidities (ie, CCI) and age were controlled for using multivariate analysis. A significant difference in the odds of rebleed persisted between the two health regions as well as for inpatient versus outpatient status. Interestingly, differences in rebleed rates were no longer observed for endoscopist specialty or time to endoscopy.

\section{DISCUSSION}

Identifying factors that contribute to mortality and rebleeding following NVUGIB is of importance to improve these outcomes. Our study examined the impact of a variety of process- and operator-dependent factors on both the mortality and 30-day rebleed rates of patients following presentation with NVUGIB in Saskatchewan's two largest health regions: the RQHR and SHR. In relation to published rates, the present study found Saskatchewan to have poor outcomes with respect to both mortality and rebleeding. While the mortality rate due to NVUGIB has generally been reported to range from $5 \%$ to $10 \%$ (2), two studies that examined data from multiple centres across Canada have reported mortality rates of $3.5 \%$ (5) and $5.4 \%(3)$. The 30 -day rebleed rate derived from observational data from 18 centres from across Canada was reported by Barkun et al (3) to be $14.1 \%$. In contrast, our data identified significantly higher rates of both mortality $(12.2 \%)$ and rebleed $(20.3 \%)$. Although both mortality and rebleed outcomes were assessed, we were able to conduct more meaningful comparative analyses for the rebleed outcome than mortality because the larger number of rebleed events allowed greater power to detect differences. The statistically significant associations that were observed between the Forrest classification and both mortality and 30-day rebleed outcomes serves as a form of validation of the accuracy of the extracted data $(6,7)$. Although we did not have the ability to stratify bleed according to clinical severity for all patients, the rate of endoscopic intervention observed in the present study was $35.5 \%$. This rate is consistent with results in previously published NVUGIB registries from Canada and the United Kingdom (3).
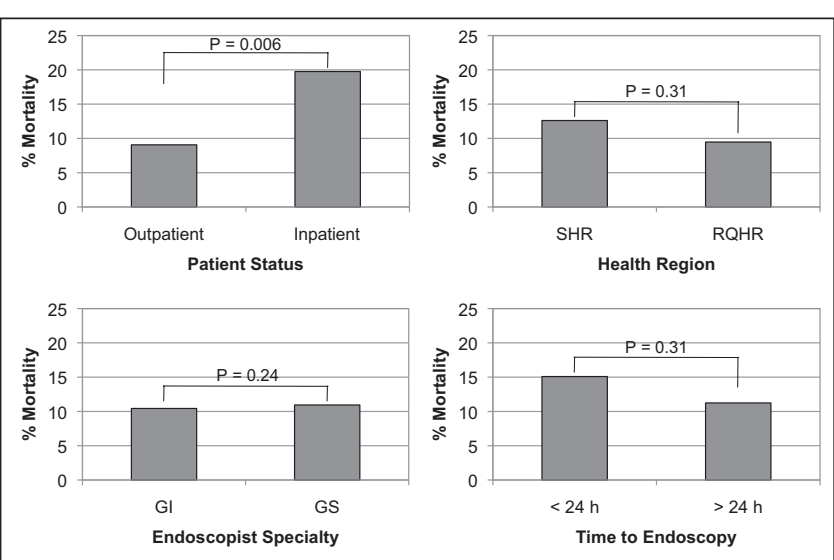

Figure 1) Mortality in patients presenting with nonvariceal upper gastrointestinal bleeding in the Saskatoon Health Region (SHR) and Regina Qu'Appelle health regions (RQHR) stratified according to patient status, health region, endoscopist specialty and time to endoscopy. The level of statistical significance is indicated by the given P value. GI Gastroenterologist; GS General surgeon
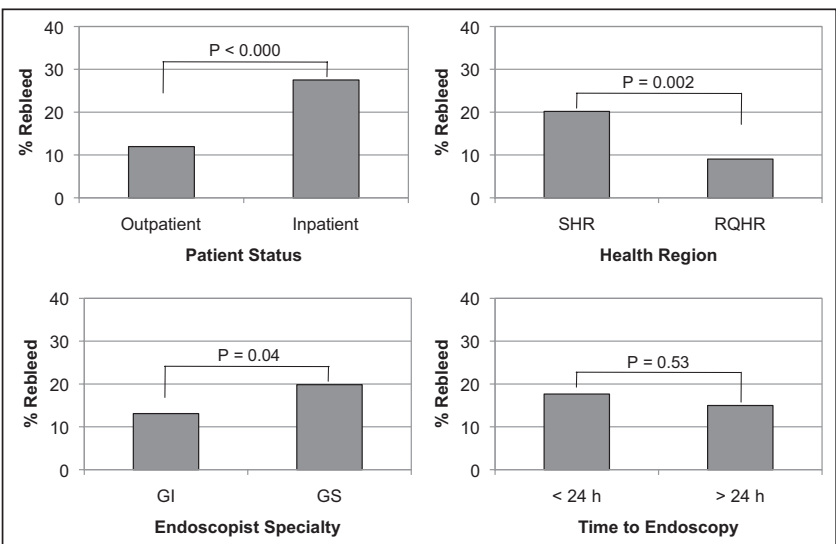

Figure 2) Thirty-day rebleed events in patients presenting with nonvariceal upper gastrointestinal bleeding in the Saskatoon Health Region (SHR) and Regina Qu'Appelle health region (RQHR) stratified according to patient status, health region, endoscopist specialty and time to endoscopy. The level of statistical significance is indicated by the given $P$ values. GI Gastroenterologist; GS General surgeon

The overall rebleed rate in the present study was found to be $20.3 \%$; however, when peptic ulcers alone were considered, the rebleed rate was $25 \%$. Although the observed breakdown of Forrest classification among ulcers was similar to that of a previous study (27), the $10 \%$ incidence of rebleed observed in ulcers reported as clean-based in our study was higher than the $3 \%$ to $5 \%$ generally reported in the literature $(28,29)$. This rebleed rate was observed despite the administration of PPIs to 94.4\% of the patients included in the present study, $91.5 \%$ of whom received this intervention intravenously at some point during their admission. Not only has the use of PPIs been shown to decrease rebleeding (30), but the intravenous administration of these agents in particular has been associated with significant reductions in the risk of rebleed occurring in high-risk lesions after endoscopy (31). Therefore, the high incidence of rebleed observed in our study, especially in lesions described as clean based, suggests that in some cases, the endoscopist may have failed to recognize high-risk lesions or that the documentation of the endoscopic stigmata was inaccurate. In fact, interobserver variability in the classification of peptic ulcers has been reported to be high depending on the years of experience and number of procedures performed by the endoscopist (32).

Endoscopist experience has also been associated with significant reductions in rebleed events (16). Although we were not able to 
demonstrate significant differences in the odds of rebleed events between endoscopist specialty, endoscopic experience may still play a role in the recording of endoscopic observations as well as endoscopic therapeutic decisions. Although we were unable to evaluate endoscopic experience for all endoscopists involved, it is plausible that the two to three years of endoscopic training received during a gastroenterology fellowship, including a concentrated exposure to therapeutic endoscopy, may lead to more endoscopic experience and familiarity with hemostatic accessories, and perhaps better outcomes.

After multivariate analysis, early endoscopy was not found to have a significant association with decreased rebleeding in our study. This observation is inconsistent with the findings of a previous study that examined the effectiveness of early endoscopy in a larger sample ( $\mathrm{n}=909$ ), which demonstrated that endoscopy performed within $24 \mathrm{~h}$ decreased the risk of recurrent bleeding (13). The reasons for this, as well as the failure to demonstrate differences in rebleed risk among endoscopic specialty, are not entirely clear; however, they may relate, in part, to multicollinearity of the health region, time to endoscopy and endoscopic specialty variables within the multivariate model. Finally, our results demonstrated a significant association between inpatient status at the time of the initial bleed and both increased mortality and 30-day rebleed. This corresponds to the findings of a previous study that showed that inpatients who developed NVUGIB had a significantly higher risk of poor outcome than outpatients (33).

The lower risk of 30-day rebleed observed among patients treated in the RQHR versus the SHR could be at least partially attributed to two major systematic differences that exist in the way that care for NVUGIB was delivered at the times of the present study by these health regions. First, the RQHR employed a formal call-back endoscopy team while the SHR did not. This means that there were no dedicated gastrointestinal nurses on call in the SHR to assist physicians with therapeutic endoscopy for upper gastrointestinal bleeding. This has provided an opportunity to examine the impact of the presence or absence of such a team on mortality and 30-day rebleed due to NVUGIB. While it cannot be concluded that the availability of the formal call back endoscopy team is the sole cause of the improved outcomes observed in the RQHR, at minimum, the presence of this team likely influences the other processes that were examined in the present study. This would be consistent with the findings of a previous report that found time to endoscopy to be dependent on clinical and process factors (24). Although the consensus among world leaders in therapeutic endoscopy is that support staff trained in endoscopy should be available on an urgent basis (12), to our knowledge, no previous studies have directly compared outcomes between two health regions with such disparate process differences in the management of NVUGIB. Our findings demonstrate that there is a strong association between decreased risk of rebleed following NVUGIB and both the availability of trained support staff and early endoscopy.

The second significant difference between NVUGIB treatment in the SHR and RQHR is that a higher proportion of endoscopies in the RQHR were performed by gastroenterologists as opposed to general surgeons. This further supports the notion that there is a decreased risk of rebleeding following therapeutic endoscopy with increased endoscopist experience (16). Having one service responsible for NVUGIB care would presumably lead to a higher volume of patients being treated by more experienced endoscopists, thereby contributing to improved outcomes.

The limitations of our study include its retrospective nature and small sample size, which restricted our ability to detect operator and regional differences in the mortality rate related to NVUGIB. Mortality related to upper gastrointestinal hemorrhage is preceded by recurrent gastrointestinal bleeding that either leads to death itself or precipitates other acute events that cause death; however, much larger studies would be required to explore the influence of health region and endoscopic operator on NVUGIB-related mortality. Another weakness of our study was that Helicobacter pylori status was not discerned. Because the treatment of $\mathrm{H}$ pylori is known to be protective against rebleeding, the management of $\mathrm{H}$ pylori may account for some of the differences apparent in our data. The probable presence of multicollinearity among endoscopist specialty, time to EGD and health region in our multivariate logistic regression model may have resulted in inaccurate estimates of the rebleed risk associated with time to EGD and endoscopist specialty. Despite these limitations, our results suggest that process factors play a significant role in NVUGIB outcomes.

\section{CONCLUSION}

The present study has exposed higher than expected rates of NVUGIB mortality in Saskatchewan, as well as significant differences in the rates of 30-day rebleeding between the Saskatchewan health regions examined in the present study and previous Canadawide registries. The regional differences in the proportion of rebleeding events observed in the present study persisted after controlling for potentially confounding covariates (CCI comorbidity and patient age). Further prospective studies examining the impact of health region differences and endoscopic operator on NVUGIB outcomes are, therefore, warranted and could lead to improvements in regional health care policies, changes in the structure and allocation of resources for the treatment of NVUGIB and, ultimately, improved outcomes.

DISCLOSURES: The authors have no financial disclosures or conflicts of interest to declare.

\section{REFERENCES}

1. Rockall TA, Logan RF, Devlin HB, Northfield TC. Incidence of and mortality from acute upper gastrointestinal haemorrhage in the United Kingdom. Steering Committee and members of the National Audit of Acute Upper Gastrointestinal Haemorrhage. BMJ 1995;311:222-6.

2. Longstreth GF. Epidemiology of hospitalization for acute upper gastrointestinal hemorrhage: A population-based study. Am J Gastroenterol 1995;90:206-10.

3. Barkun A, Sabbah S, Enns R, et al. The Canadian Registry on Nonvariceal Upper Gastrointestinal Bleeding and Endoscopy (RUGBE): Endoscopic hemostasis and proton pump inhibition are associated with improved outcomes in a real-life setting. Am J Gastroenterol 2004;99:1238-46.

4. Sarin N, Monga N, Adams PC. Time to endoscopy and outcomes in upper gastrointestinal bleeding. Can J Gastroenterol 2009;23:489-93.

5. Targownik LE, Nabalamba A. Trends in management and outcomes of acute nonvariceal upper gastrointestinal bleeding: 1993-2003. Clin Gastroenterol Hepatol 2006;4:1459-66.

6. Rockall TA, Logan RF, Devlin HB, Northfield TC. Risk assessment after acute upper gastrointestinal haemorrhage. Gut 1996;38:316-21.

7. Blatchford O, Murray WR, Blatchford M. A risk score to predict need for treatment for upper-gastrointestinal haemorrhage. Lancet 2000;356:1318-21.

8. Stanley AJ, Ashley D, Dalton HR, et al. Outpatient management of patients with low-risk upper-gastrointestinal haemorrhage: Multicentre validation and prospective evaluation. Lancet 2009;373:42-7.

9. Soncini M, Triossi O, Leo P, et al. Management of patients with nonvariceal upper gastrointestinal hemorrhage before and after the adoption of the Rockall score, in the Italian Gastroenterology Units. Eur J Gastroenterol Hepatol 2007;19:543-7.

10. Lee JG, Turnipseed S, Romano PS, et al. Endoscopy-based triage significantly reduces hospitalization rates and costs of treating upper GI bleeding: a randomized controlled trial. Gastrointest Endosc 1999;50:755-61.

11. Spiegel BM, Vakil NB, Ofman JJ. Endoscopy for acute nonvariceal upper gastrointestinal tract hemorrhage: Is sooner better? A systematic review. Arch Intern Med 2001;161:1393-404.

12. Barkun AN, Bardou M, Kuipers EJ, et al. International consensus recommendations on the management of patients with nonvariceal upper gastrointestinal bleeding. Ann Intern Med 2010;152:101-13.

13. Cooper GS, Chak A, Way LE, et al. Early endoscopy in upper gastrointestinal hemorrhage: Associations with recurrent bleeding, 
surgery, and length of hospital stay. Gastrointest Endosc 1999;49:145-52.

14. Ananthakrishnan AN, McGinley EL, Saeian K. Outcomes of weekend admissions for upper gastrointestinal hemorrhage: A nationwide analysis. Clin Gastroenterol Hepatol 2009;7:296-302e1.

15. Leontiadis GI, Sreedharan A, Dorward S, et al. Systematic reviews of the clinical effectiveness and cost-effectiveness of proton pump inhibitors in acute upper gastrointestinal bleeding. Health Technol Assess 2007;11:iii-iv, 1-164.

16. Parente F, Anderloni A, Bargiggia S, et al. Outcome of non-variceal acute upper gastrointestinal bleeding in relation to the time of endoscopy and the experience of the endoscopist: A two-year survey. World J Gastroenterol 2005;11:7122-30.

17. Dorn SD, Shah ND, Berg BP, Naessens JM. Effect of weekend hospital admission on gastrointestinal hemorrhage outcomes. Dig Dis Sci 2010;55:1658-66.

18. Ananthakrishnan AN, McGinley EL, Saeian K. Higher hospital volume is associated with lower mortality in acute nonvariceal upper-GI hemorrhage. Gastrointest Endosc 2009;70:422-32.

19. Kohn A, Ancona C, Belleudi V, et al. The impact of endoscopy and specialist care on 30-day mortality among patients with acute nonvariceal upper gastrointestinal hemorrhage: An Italian populationbased study. Dig Liver Dis 2010;42:629-34.

20. Sandel MH, Kolkman JJ, Kuipers EJ, Cuesta MA, Meuwissen SG. Nonvariceal upper gastrointestinal bleeding: Differences in outcome for patients admitted to internal medicine and gastroenterological services. Am J Gastroenterol 2000;95:2357-62.

21. Sanders DS, Perry MJ, Jones SG, et al. Effectiveness of an uppergastrointestinal haemorrhage unit: A prospective analysis of 900 consecutive cases using the Rockall score as a method of risk standardisation. Eur J Gastroenterol Hepatol 2004;16:487-94.

22. Quirk DM, Barry MJ, Aserkoff B, Podolsky DK. Physician specialty and variations in the cost of treating patients with acute upper gastrointestinal bleeding. Gastroenterology 1997;113:1443-8.
23. Sanderson JD, Taylor RF, Pugh S, Vicary FR. Specialized gastrointestinal units for the management of upper gastrointestinal haemorrhage. Postgrad Med J 1990;66:654-6.

24. da Silveira EB, Lam E, Martel M, Bensoussan K, Barkun AN. The importance of process issues as predictors of time to endoscopy in patients with acute upper-GI bleeding using the RUGBE data. Gastrointest Endosc 2006;64:299-309.

25. Moayyedi P, Tepper J, Hilsden R, Rabeneck L. International comparisons of manpower in gastroenterology. Am J Gastroenterol 2007;102:478-81.

26. Charlson ME, Pompei P, Ales KL, MacKenzie CR. A new method of classifying prognostic comorbidity in longitudinal studies: Development and validation. J Chronic Dis 1987;40:373-83.

27. Guglielmi A, Ruzzenente A, Sandri M, et al. Risk assessment and prediction of rebleeding in bleeding gastroduodenal ulcer. Endoscopy 2002;34:778-86.

28. Laine L, Peterson WL. Bleeding peptic ulcer. N Engl J Med 1994;331:717-27.

29. Savides TJ, Jensen DM. Gastrointestinal Bleeding. In: Feldman M, Friedman LS, Brandt LJ, eds. Sleisenger and Fordtran's Gastrointestinal and Liver Disease, 9th edn. Philadelphia: Saunders Elsevier, 2010:285-322.

30. Leontiadis GI, Sharma VK, Howden CW. Systematic review and meta-analysis of proton pump inhibitor therapy in peptic ulcer bleeding. BMJ 2005;330:568.

31. Lau JY, Sung JJ, Lee KK, et al. Effect of intravenous omeprazole on recurrent bleeding after endoscopic treatment of bleeding peptic ulcers. N Engl J Med 2000;343:310-6.

32. Laine L, Freeman M, Cohen H. Lack of uniformity in evaluation of endoscopic prognostic features of bleeding ulcers. Gastrointest Endosc 1994:40:411-7.

33. Lanas A, Aabakken L, Fonseca J, et al. Clinical predictors of poor outcomes among patients with nonvariceal upper gastrointestinal bleeding in Europe. Aliment Pharmacol Ther 2011;33:1225-33. 


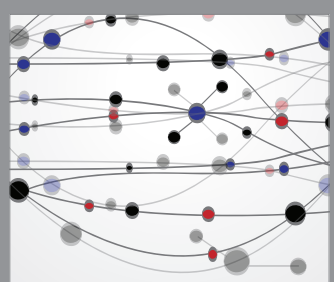

The Scientific World Journal
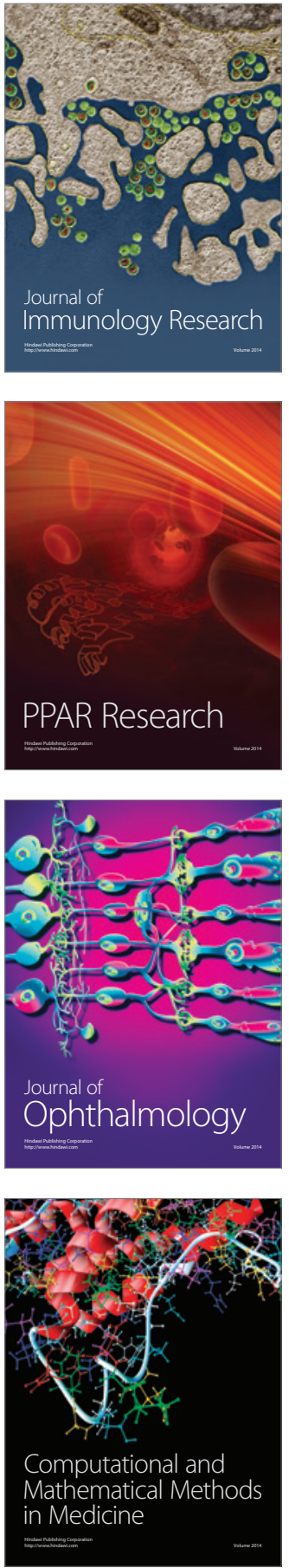

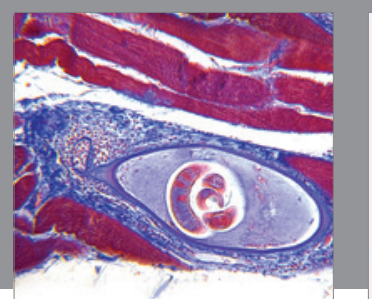

Gastroenterology Research and Practice

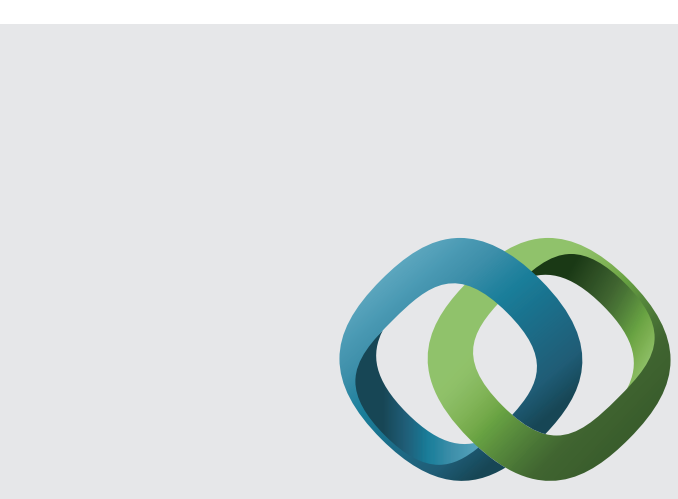

\section{Hindawi}

Submit your manuscripts at

http://www.hindawi.com
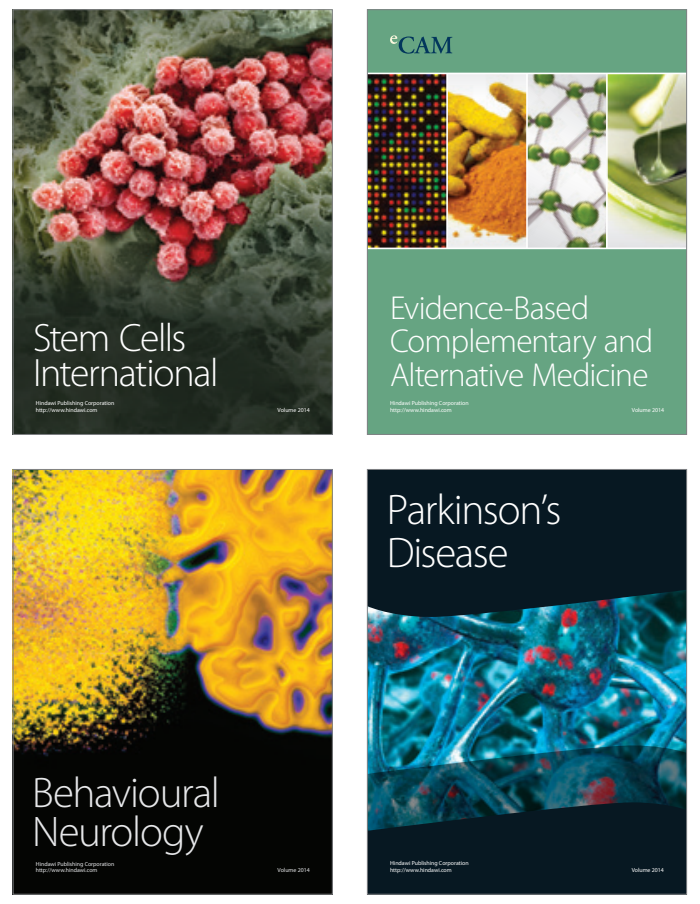
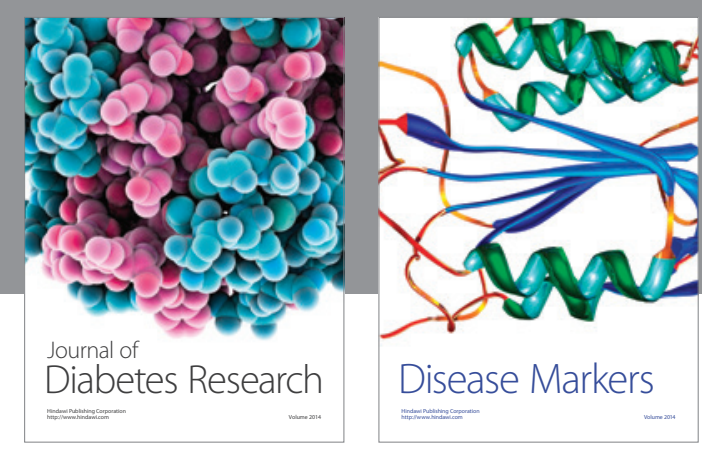

Disease Markers
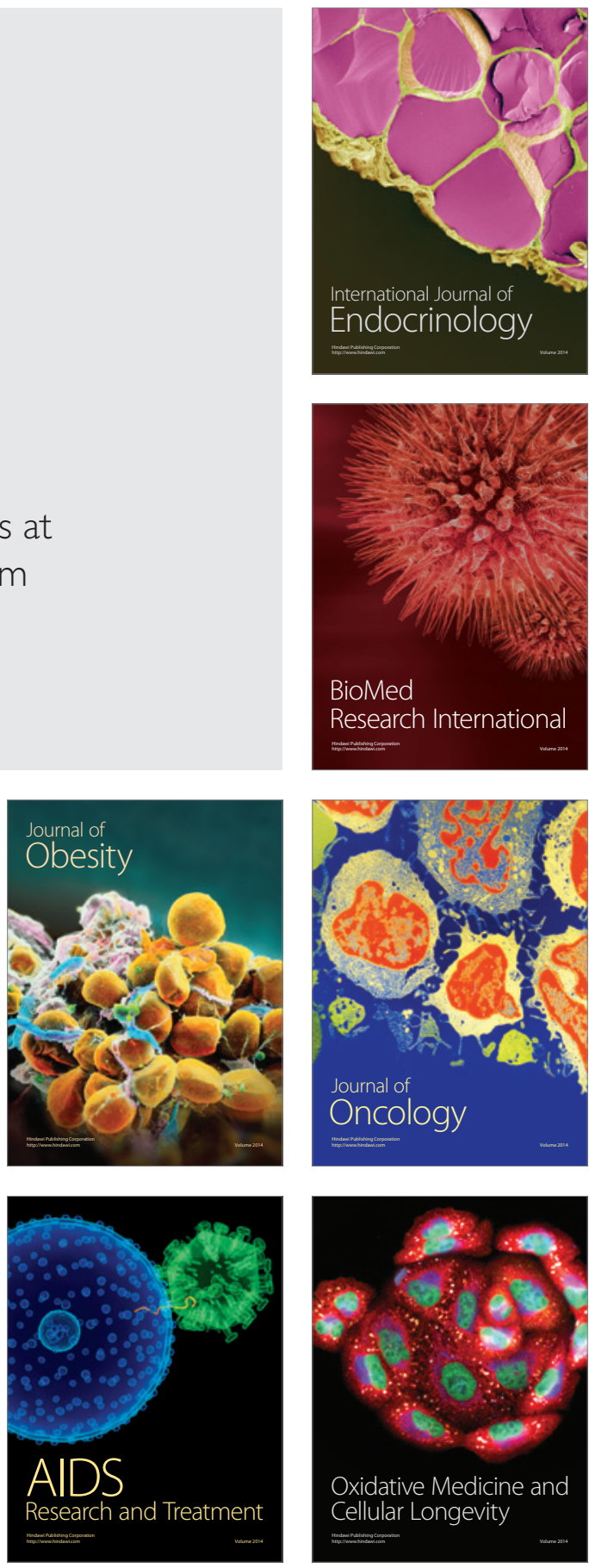